\title{
Prescribed targets for titration of vasopressors in septic shock: a retrospective cohort study
}

\author{
Charles St-Arnaud MD, Jean-François Éthier MD MSc, Cindy Hamielec MD, Andrew Bersten MD, \\ Gordon Guyatt MD MSc, Maureen Meade MD MSc, Qi Zhou PhD, Marc-André Leclair MD, \\ Alpesh Patel MD, François Lamontagne MD MSc
}

\section{Abstract}

Background: Without robust clinical evidence to guide titration of vasopressors in septic shock, it is unclear how dosing of these potent medications occurs. We sought to measure the proportion of vasopressor prescriptions for septic shock that were missing explicit targets and to describe the targets that we identified.

Methods: We conducted a multicentre, retrospective cohort study involving 9 intensive care units (ICUs) located at 3 academic hospitals in Canada and Australia. We reviewed charts of consecutive patients aged 18 years or older who were admitted to the ICU for a presumptive diagnosis of sepsis. Other inclusion criteria were hypotension (systolic arterial pressure $\leq 90 \mathrm{~mm} \mathrm{Hg}$ or mean arterial pressure $[\mathrm{MAP}] \leq 65 \mathrm{~mm} \mathrm{Hg}$ ) and continuous infusion of vasopressors for at least 1 hour within the initial 48 hours of ICU stay, the period of observation for this study.

Results: We included data from 369 patient charts. At least 1 target was specified in $99 \%$ of charts. The most common targets were MAP measurements (73\%). The median initial MAP target was 65 (range 55-90) mm Hg. In multivariable regression models, hospital site and older age of the patient, but not comorbidities of the patient, were associated with MAP targets. In $40 \%$ of patients, the treating team modified the initial target at least once.

Interpretation: This study suggests that an explicit blood pressure target accompanies nearly every vasopressor prescription and that patient characteristics have little influence on its value. Identification of a titration strategy that will maximize benefit and minimize harm constitutes a research priority.

evere sepsis and septic shock are frequently encountered pathologies, and their incidence is rising in modern intensive care units (ICUs). ${ }^{1,2}$ With septic shock, hemodynamic instability ensues, which leads to a state of circulatory failure that persists despite fluid resuscitation. In healthy individuals, autoregulation maintains blood flow to vascular beds despite variations in arterial pressure. In septic shock, a common pathophysiological model is based on animal studies of limited clinical relevance. ${ }^{3}$ This model suggests that blood pressure may decrease to a critical level below which tissue perfusion becomes linearly dependent on arterial pressure..$^{4-6}$ The rationale underlying vasopressor therapy in this context is to increase arterial blood pressure to restore and maintain adequate tissue perfusion. However, the specific blood pressure threshold below which perfusion is compromised and the ideal target for vasopressor titration are not known. Drawing on expert opinions, current guidelines issued by the Surviving Sepsis Campaign recommend a minimum mean arterial pressure (MAP) value of $65 \mathrm{~mm} \mathrm{Hg}$ in septic shock..$^{5-7}$ However, to our knowledge, no study has shown that targeting a MAP value above $65 \mathrm{~mm} \mathrm{Hg}$ as opposed to another blood pressure value was beneficial..$^{8-11}$ Accordingly, the optimal blood pressure value could vary for different patients and depend on which organ systems are monitored. Without robust clinical evidence to guide titration of vasopressors in septic shock, it is unclear how to adjust the dosing of these potent medications, and variations in practice are expected.

In a survey about treatment of septic shock, Canadian intensivists reported that they typically aimed for a MAP value of $65 \mathrm{~mm} \mathrm{Hg}$, that they targeted higher blood pressure values in the presence of signs of malperfusion, and that chronic comorbidities and acute concurrent illnesses influenced their

Competing interests: None declared.

This article has been peer reviewed.

Correspondence to: François Lamontagne, francois.lamontagne@usherbrooke.ca

CMAJ Open 2013.DOI:10.9778/cmajo.20130006 
selection of blood pressure targets. ${ }^{12}$ However, differences may exist between actual practice and responses to a survey. The primary objectives of our study were to measure the proportion of patients with septic shock for whom physicians used explicit targets when prescribing vasopressors and to compare these with practice recommendations. We hypothesized that explicit blood pressure targets would be missing from half of the vasopressor prescriptions. Secondary objectives were to describe associations between prescribed targets and patients' chronic comorbidities and acute concurrent illnesses.

\section{Methods}

\section{Centres and patients}

We performed a retrospective cohort study in 9 universityaffiliated ICUs located at 3 tertiary care hospitals in Canada and Australia. None of the centres used standardized order forms for vasopressors. The hospitals' research ethics boards approved the study and waived the need for informed consent for this retrospective chart audit.

To identify patients who received vasopressors for septic shock, at the centre in Australia, we screened the ICU database for diagnoses of septic shock; at the centres in Canada, we screened the record of every patient who had received both antibiotics and vasopressors at any time during their ICU stay. The different screening strategies were owing to differences in data collection at participating ICUs in the 2 countries. We then reviewed the charts and included those of patients who were 18 years or older and were admitted to the ICU specifically for a presumptive diagnosis of sepsis (as initially recorded in the medical notes). The dominant diagnosis at the time of admission determined the presumptive source of infection in this study. We sought explicit statements in the medical notes from the first day in the ICU to confirm that septic shock was the dominant working diagnosis at the time of admission (e.g., the identification of septic shock or diagnoses potentially associated with septic shock as the main working diagnosis at the time of ICU admission). Other inclusion criteria were at least 1 episode of hypotension (systolic arterial pressure $[\mathrm{SAP}] \leq 90$ mm $\mathrm{Hg}$ or MAP $\leq 65 \mathrm{~mm} \mathrm{Hg}$; duration not specified) and a continuous infusion of vasopressors for at least 1 hour within the initial 48 hours of ICU stay. We excluded charts of patients who received treatment outside the ICU (e.g., the coronary care and step-down units) and patients who, although they later had septic shock, were initially admitted to the ICU for other reasons.

\section{Data collection}

At each centre, investigators manually reviewed charts and extracted data using prepiloted electronic forms with logical checks for extreme or missing values. Every investigator received a detailed instruction manual. We collected information about patient demographics, source of infection, Acute Physiology and Chronic Health Evaluation II (APACHE II) score, ${ }^{13}$ baseline chronic comorbidities, concurrent acute illnesses and targets for vasopressor titration. To capture all targets, including those that may have been spoken instead of written by the medical team, we reviewed medical and nursing progress notes as well as written orders. We included vasopressor prescriptions made by any ICU team member within the initial 48 hours of ICU stay, but excluded prescriptions made before the patient was under the care of the intensivist (e.g., prescriptions written by the emergency physicians were excluded). To ensure data quality, investigators received data queries when the automated data entry system identified extreme or missing values.

\section{Definitions}

In this study, we defined vasopressors as any of the following medications administered for at least 1 hour: norepinephrine, epinephrine, vasopressin, dopamine and phenylephrine. We included every target specified during the initial 48 hours of ICU stay. Chronic comorbidities correspond to pathologies diagnosed before hospital admission (i.e., peripheral vascular disease, coronary artery disease, heart failure, chronic obstructive pulmonary disease, asthma, hypertension, diabetes mellitus, chronic renal failure, cirrhosis, obesity, neoplasia and immunosuppression). We classified new illnesses diagnosed within 48 hours of ICU admission as acute concurrent illnesses (i.e., stroke, myocardial injury, cardiac arrhythmia, acute pulmonary edema, acute respiratory distress syndrome, acute lung injury, massive hemorrhage, ischemic bowel disease, acute renal failure, maximal lactic acid level $\geq 4.0$ $\mathrm{mmol} / \mathrm{L}$ and maximal international normalized ratio $\geq 2.0$ ). Appendix 1 available at www.cmajopen.ca/content/1/4 /E127/suppl/DC1 provides definitions for comorbidities.

\section{Statistical analysis}

We report continuous variables as means and $95 \%$ confidence intervals (CIs) or medians and interquartile ranges (IQRs), and categorical variables as proportions. We assumed patients to be free of specific comorbidities and acute illnesses when we found no report of these. For between-centre comparisons of continuous variables, we used the analysis of variance $F$ test. For between-centre comparisons of categorical data, we used the $\chi^{2}$ or the Fisher exact test when the samples were small.

To assess the association between chronic comorbidities and the first vasopressor titration target, we built a multivariable linear regression model with the first blood pressure target as the dependent variable. We introduced hospital centre (fixed effects), admission APACHE II score, age, coronary artery disease, chronic heart failure, chronic hypertension, diabetes and chronic renal failure simultaneously as independent variables. To avoid overfitting, we ran this model strictly with targets expressed as MAPs because other targets like SAPs were rare. To assess the association between acute concurrent illnesses and modifications of vasopressor titration targets, we built a multinomial logistic regression model with a 3 category dependent variable (initial blood pressure target decreased, unchanged or increased). Cases were included in this analysis if the initial blood pressure target was either not modified or modified numerically with no modification of the target variable (MAP to MAP or SAP to SAP). Hospital centre (fixed effects), acute renal failure, myocardial injury, serum 
lactate level $4 \mathrm{mmol} / \mathrm{L}$ or greater, and cardiac arrhythmia were the independent variables simultaneously introduced in the model. We selected candidate independent variables for both models a priori, based on clinical plausibility and availability in the charts.

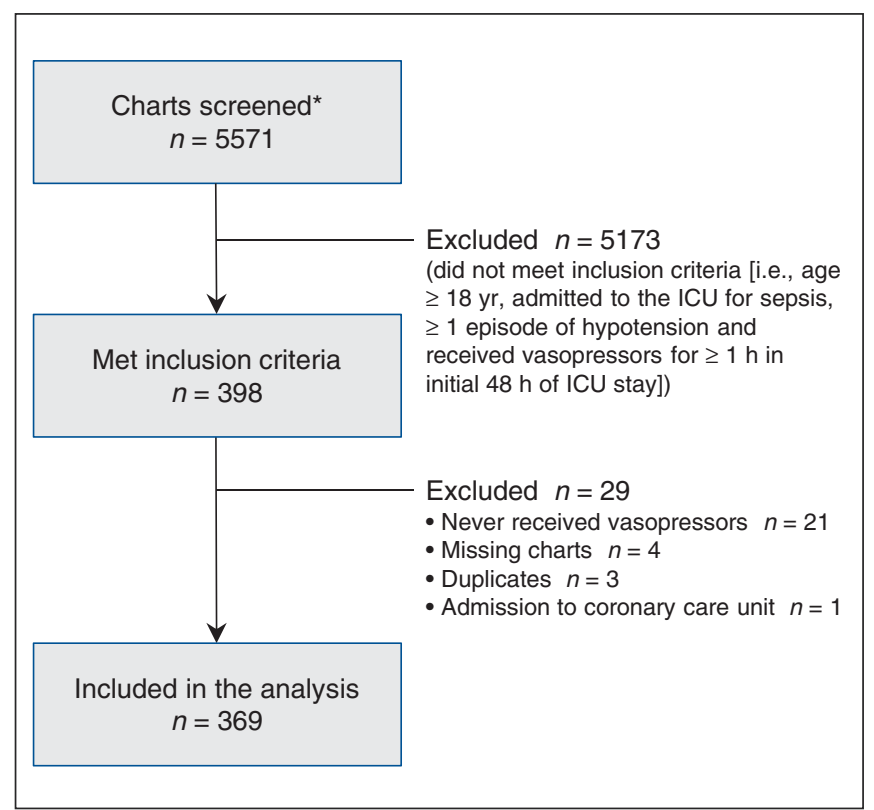

Figure 1: Flow diagram of charts included for review. *In Australia, we screened the intensive care unit (ICU) database for diagnoses of septic shock. In Canada, we screened charts of patients who had received both antibiotics and vasopressors at some time during their ICU stay.

\section{Sample size}

We assumed conservatively that we would find explicit targets for the titration of vasopressors in $50 \%$ of the charts. Following this a priori assumption, a sample of 235 patient charts would provide 117 explicit targets. In addition, this sample would have provided more than $90 \%$ power to detect a $3 \mathrm{~mm}$ $\mathrm{Hg}$ difference between the mean of prescribed targets and current practice guidelines to target $65 \mathrm{~mm} \mathrm{Hg}$. The number of charts reviewed per site was not preset. Investigators at each centre proceeded at their own pace until the total number of included charts exceeded the planned sample size. The decision to terminate data extraction was made before analyzing the data (without any knowledge of the results).

\section{Results}

We screened 5571 patient charts and selected 398 for manual review. We excluded 29 charts and included data from 369 patient charts in the final analysis (Figure 1). The mean patient age was 65 (95\% CI 63 to 66) years, 53\% were male and the mean APACHE II score was 27 (95\% CI 26 to 28). Age and sex did not differ among centres, but the mean APACHE II score was higher at centre 2 (32 [95\% CI 30 to $33])$ than at centres 1 (24 [95\% CI 23 to 25]) and 3 (24 [95\% CI 22 to 26]) $(p<0.001)$. About half $(51 \%)$ of patients were admitted directly from the emergency department, and the lungs, the gastrointestinal tract and the genitourinary system were the most common sources of infection.

The most common chronic comorbidities (Table 1) were hypertension $(56 \%)$, diabetes mellitus $(31 \%)$ and coronary

Table 1: Chronic comorbidities of adult patients admitted to the intensive care unit for sepsis

\begin{tabular}{|c|c|c|c|c|c|}
\hline \multirow[b]{2}{*}{ Variable } & \multicolumn{4}{|c|}{$\%(\text { no. })^{*}$} & \multirow[b]{2}{*}{$p$ value } \\
\hline & $\begin{array}{c}\text { All patients } \\
n=369\end{array}$ & $\begin{array}{c}\text { Centre } 1 \\
n=174\end{array}$ & $\begin{array}{c}\text { Centre } 2 \\
n=114\end{array}$ & $\begin{array}{c}\text { Centre } 3 \\
n=81\end{array}$ & \\
\hline Hypertension & $56(205)$ & $51(88)$ & $66(75)$ & $52(42)$ & 0.03 \\
\hline Diabetes mellitus & $31(115)$ & $29(51)$ & $31(35)$ & $36(29)$ & 0.6 \\
\hline Coronary artery disease & $31(113)$ & $30(52)$ & $38(43)$ & $22(18)$ & 0.07 \\
\hline Chronic obstructive pulmonary disease & $25(94)$ & $28(49)$ & $21(24)$ & $26(21)$ & 0.4 \\
\hline Peripheral vascular disease & $19(71)$ & $22(38)$ & $24(27)$ & $7(6)$ & 0.01 \\
\hline Immunosuppression & $18(68)$ & $17(30)$ & $11(13)$ & $31(25)$ & 0.002 \\
\hline Chronic renal failure & $18(66)$ & $14(25)$ & $13(15)$ & $32(26)$ & 0.001 \\
\hline Heart failure & $18(65)$ & $15(26)$ & $21(24)$ & $19(15)$ & 0.4 \\
\hline Neoplasia & $17(64)$ & $21(36)$ & $8 \quad(9)$ & $23(19)$ & 0.01 \\
\hline Cirrhosis & $8(29)$ & $5 \quad(9)$ & $11(12)$ & $10(8)$ & 0.2 \\
\hline Asthma & $4(16)$ & $2 \quad(3)$ & $3 \quad(3)$ & $12(10)$ & 0.001 \\
\hline No. of comorbidities per patient, median (IQR) & $3(1$ to 4$)$ & $2(1$ to 4$)$ & $3(1$ to 4$)$ & $3(2$ to 4$)$ & 1.0 \\
\hline Patients with no chronic comorbidity & $10 \quad(38)$ & $12(21)$ & $11(13)$ & $5 \quad(4)$ & 0.2 \\
\hline Patients with $\geq 1$ chronic comorbidities & $90(331)$ & $88(153)$ & $89(101)$ & $95(77)$ & 0.2 \\
\hline Patients with $\geq 2$ chronic comorbidities & $71(263)$ & $67(117)$ & $70(80)$ & $81(66)$ & 0.06 \\
\hline
\end{tabular}


Table 2: Concurrent acute illnesses of adult patients admitted to the intensive care unit for sepsis

\begin{tabular}{|c|c|c|c|c|c|}
\hline Variable & \multicolumn{4}{|c|}{$\%(\text { no. })^{*}$} & $p$ value \\
\hline Acute renal failure & $61(224)$ & $62(108)$ & 72 (82) & $42(34)$ & $<0.001$ \\
\hline Myocardial infarction & $35(128)$ & $33 \quad(57)$ & 59 (67) & 5 (4) & $<0.001$ \\
\hline Maximal serum lactic acid $\geq 4.0 \mathrm{mmol} / \mathrm{L}$ & $35(128)$ & $24 \quad(41)$ & $48 \quad(55)$ & $40(32)$ & $<0.001$ \\
\hline Cardiac arrhythmia & $24(89)$ & $18 \quad(32)$ & $22(25)$ & $40(32)$ & 0.001 \\
\hline Maximal INR $\geq 2.0$ & $23(84)$ & $14(24)$ & 34 (39) & $26(21)$ & $<0.001$ \\
\hline Acute pulmonary edema & $17 \quad(61)$ & $17 \quad(29)$ & $11(13)$ & $23(19)$ & 0.08 \\
\hline Massive hemorrhage & $13(48)$ & $21(37)$ & $9(10)$ & $1(1)$ & $<0.001$ \\
\hline Ischemic bowel disease & $6(23)$ & $8(14)$ & $4 \quad(5)$ & 5 (4) & 0.5 \\
\hline Patients with $\geq 1$ concurrent acute illnesses & $91(335)$ & $91(159)$ & $96(110)$ & $81(66)$ & 0.002 \\
\hline Patients with $\geq 2$ concurrent acute illnesses & $72(265)$ & $70(121)$ & $85(97)$ & $58(47)$ & $<0.001$ \\
\hline
\end{tabular}

Table 3: Prescribed targets for the titration of vasopressors*

$$
\% \text { (no.) }[95 \% \mathrm{Cl}] \dagger
$$

\begin{tabular}{|c|c|c|c|c|c|}
\hline \multirow[b]{2}{*}{ Variable } & & \multirow[b]{2}{*}{$p$ value } \\
\hline & All sites & Centre 1 & Centre 2 & Centre 3 & \\
\hline No. of patients & 369 & 174 & 114 & 81 & - \\
\hline Total no. of targets analyzed & 604 & 277 & 176 & 151 & - \\
\hline Patients with $\geq 1$ targets & 99 (365) [98 to 100] & 99 (173) [97 to 100] & 99 (113) [95 to 100] & $98(79)[94$ to 100$]$ & 0.4 \\
\hline All targets $\ddagger$ & $n=604$ & $n=277$ & $n=176$ & $n=151$ & $<0.001$ \\
\hline SAP is only target & 16 (95) [13 to 19] & 6 (18) [4 to 9] & 43 (75) [35 to 49] & 1 (2) [0 to 3] & \\
\hline MAP is only target & 73 (438) [69 to 76$]$ & 79 (220) [75 to 84] & 39 (69) [33 to 47] & 99 (149) [97 to 100] & \\
\hline SAP and MAP combined & 8 (50) [6 to 11] & 14 (38) [10 to 18$]$ & 7 (12) [3 to 11] & (0) & \\
\hline Other & 3 (21) [2 to 5] & 0.4 (1) [0 to 2] & $11(20)[7$ to 16$]$ & (0) & \\
\hline First target only§ & $n=365$ & $n=173$ & $n=113$ & $n=79$ & $<0.001$ \\
\hline SAP is only target & $16 \quad(58)[12$ to 20$]$ & $3 \quad$ (6) $[1$ to 6$]$ & 45 (51) [36 to 54] & 1 (1) [0 to 4] & \\
\hline MAP is only target & 75 (273) [70 to 79$]$ & 83 (144) [78 to 89] & $45(51)$ [36 to 54$]$ & 99 (78) [96 to 100] & \\
\hline SAP and MAP combined & 7 (27) [5 to 10$]$ & 13 (23) [8 to 18] & 4 (4) [0 to 7] & (0) & \\
\hline Other & 2 (7) [1 to 3] & (0) & 6 (7) [3 to 12] & (0) & \\
\hline \multicolumn{6}{|l|}{ Target value (first targets only) } \\
\hline SAP only, mm Hg, median (IQR) & $\begin{array}{c}100(90 \text { to } 100) \\
n=58\end{array}$ & $\begin{array}{c}100(90 \text { to } 100) \\
n=6\end{array}$ & $\begin{array}{c}100(90 \text { to } 10) \\
n=51\end{array}$ & $\begin{array}{c}120(120 \text { to } 120) \\
n=1\end{array}$ & 0.04 \\
\hline MAP only, mm Hg, median (IQR) & $\begin{array}{c}65(65 \text { to } 70) \\
n=273\end{array}$ & $\begin{array}{c}65(65 \text { to } 65) \\
n=144\end{array}$ & $\begin{array}{c}65 \text { (65 to } 70) \\
n=51\end{array}$ & $\begin{array}{c}70(70 \text { to } 75) \\
n=78\end{array}$ & $<0.001$ \\
\hline \multicolumn{6}{|c|}{$\begin{array}{l}\text { Note: } \mathrm{Cl}=\text { confidence interval, } \mathrm{IQR}=\text { interquartile range, } \mathrm{MAP}=\text { mean arterial pressure, } \mathrm{SAP}=\text { systolic arterial pressure. } \\
{ }^{*} \text { Vasopressor targets are values of physiologic variables (e.g., specific blood pressure values) that physicians set as goals of care and achieve by dosing continuous } \\
\text { infusions of vasopressors. } \\
\text { †Unless stated otherwise. } \\
\text { †Denominator is total no. of targets analyzed. } \\
\S \text { Denominator is no. of patients with } \geq 1 \text { targets. }\end{array}$} \\
\hline
\end{tabular}


artery disease (31\%). Although the type of chronic comorbidities encountered at the 3 centres varied, the total number of comorbidities per patient was similar across all centres (median 3 [IQR 1 to 4]). The most common acute concurrent illnesses were acute renal failure (61\%), myocardial infarction (35\%), hyperlactatemia (35\%) and acute respiratory distress syndrome or acute lung injury (31\%) (Table 2). Again, we observed differences among centres. Overall, the median number of acute concurrent illnesses per patient at centre 2 (3 [IQR 2 to 4]) was greater than at centres 1 (2 [IQR 1 to 3]) or 3 (2 [IQR 1 to 3$])(p<0.001)$.

Table 3 presents specific targets for the titration of vasopressors. We found 604 explicit targets corresponding to the study period (within 48 hours of ICU admission). At least 1 explicit target was specified for 99\% (365) of the patients. Most targets were values of MAP (73\%), SAP (16\%) and a combination of MAP and SAP (8\%). Other targets were rare: blood pressure ranges $(2 \%)$, systemic vascular indices of resistance $(0.5 \%)$, heart rates $(0.4 \%)$ and dopamine at fixed renal dose $(0.2 \%)$. None of the 604 prescriptions targeted urine output, lactate levels, mental status or central venous oxygen saturation. Of the 365 initial targets, 273 (75\%) were MAP. Overall, the initial MAP targets ranged from 55 to $90 \mathrm{~mm} \mathrm{Hg}$ and the median was 65 (IQR 65 to 70) $\mathrm{mm} \mathrm{Hg}$. Higher MAP values were initially targeted at centre 3 (median MAP 70 [IQR 70 to 75] mm Hg; $p<0.001$ v. other centres) (Appendix 2 available at www.cmajopen.ca/content/1/4/E127/suppl /DC1). Table 4 presents the results of a multivariable linear regression model measuring the association between baseline variables and the value of initial MAP targets. The only variables associated with initial MAP values were patient age and hospital site, whereas older age was associated with high blood pressure targets.

For $40 \%$ of the patients $(n=148)$ the medical team modified the initial target at least once. In $54 \%$ of these (80/148) patients, the new target consisted of different values of the same blood pressure variable (MAP to MAP or SAP to SAP). We found that, of these target modifications, 41\% (33/80) represented increases from the original prescribed targets, whereas 59\% (47/80) were reductions (Table 5). In a multivariable logistic regression, we found no association between the acute concurrent illnesses and target modifications in either direction (Table 6).

\section{Interpretation}

In this multicentre retrospective study conducted in 1 tertiary care centre from Australia (3 ICUs) and 2 from Canada (6 ICUs), we found that an explicit titration target accompanied nearly every vasopressor prescription. A MAP value of $65 \mathrm{~mm}$ $\mathrm{Hg}$ was the most frequent vasopressor titration target, although somewhat higher targets (typically $70 \mathrm{~mm} \mathrm{Hg}$ ) were also common and the range was wide $(55-90 \mathrm{~mm} \mathrm{Hg})$. We found differences among centres in the prescribed blood pressure variables (MAP v. SAP v. combination of MAP and SAP) and in the blood pressure values. Our data showed that physicians used explicit blood pressure targets for vasopressor dosing adjustments. Older age of the patient and local culture (i.e., the centre effect) were predictors of higher blood pressure targets although the effect of patient age was modest. We found no association between chronic comorbidities or acute concurrent illnesses and blood pressure targets. Clinicians often changed targets during the first 48 hours of the patient's ICU stay.

The finding that the dominant target is a MAP of $65 \mathrm{~mm}$ $\mathrm{Hg}$ is concordant with the results of a survey of Canadian intensivists conducted by our group. ${ }^{12}$ However, in this previous

Table 4: Multivariable linear regression model $^{\star}$ of initial mean arterial blood pressure targets for vasopressor titration $(n=273)$

\begin{tabular}{|lrl|}
\hline Parameters & \multicolumn{2}{c|}{ OR $(95 \% \mathrm{Cl})$} \\
\hline Centre 1 v. 3 & -6.93 & $(-7.94$ to 5.92$)$ \\
\hline Centre 2 v. 3 & -4.37 & $(-5.74$ to -3.00$)$ \\
\hline APACHE II score & -0.02 & $(-0.07$ to 0.04$)$ \\
\hline Age & 0.04 & $(0.01$ to 0.07$)$ \\
\hline Coronary artery disease & 0.40 & $(-0.68$ to 1.47$)$ \\
\hline Chronic heart failure & -0.48 & $(-1.69$ to 0.72$)$ \\
\hline Hypertension & -0.17 & $(-1.15$ to 0.80$)$ \\
\hline Diabetes & 0.08 & $(-0.87$ to 1.04$)$ \\
\hline Chronic renal failure & -1.11 & $(-2.26$ to 0.04$)$ \\
\hline $\begin{array}{l}\text { Note: APACHE }=\text { Acute Physiology and Chronic } \\
\text { Cl }=\text { Health Evaluation, } \\
{ }^{*} R^{2}=0.43 .\end{array}$ & & \\
\hline
\end{tabular}

Table 5: Modifications to initial targets for vasopressor titration

\begin{tabular}{|c|c|}
\hline Variable & All sites \\
\hline No. of patients & 369 \\
\hline Total no. of targets analyzed & 604 \\
\hline $\begin{array}{l}\text { Patients with } \geq 1 \text { explicit target, \% (no.) } \\
\text { [95\% Cl] }\end{array}$ & $\begin{array}{l}99(365) \\
{[98 \text { to } 100]}\end{array}$ \\
\hline \multicolumn{2}{|l|}{ Target modifications } \\
\hline $\begin{array}{l}\text { Patients with no modifications (only } 1 \text { target), } \\
\% \text { (no.) }\end{array}$ & $54(199)$ \\
\hline $\begin{array}{l}\text { Patients with } \geq 1 \text { modification of initial target, } \\
\% \text { (no.) }\end{array}$ & $40(148)$ \\
\hline \multicolumn{2}{|l|}{ Direction of target modifications } \\
\hline $\begin{array}{l}\text { Proportion of target changes in the same } \\
\text { category that represent an increase in the } \\
\text { target value, \% (no.)* }\end{array}$ & $\begin{array}{l}41(33) \\
n=80\end{array}$ \\
\hline SAP to SAP increase, $\mathrm{mm} \mathrm{Hg}$, median (IQR) & $+10(10$ to 10$)$ \\
\hline MAP to MAP increase, $\mathrm{mm} \mathrm{Hg}$, median (IQR) & $+5 \quad(5$ to 5$)$ \\
\hline $\begin{array}{l}\text { Proportion of target changes in the same } \\
\text { category that represent a decrement in the } \\
\text { target value, } \% \text { (no. })^{\star}\end{array}$ & $\begin{array}{l}59(47) \\
n=80\end{array}$ \\
\hline SAP to SAP decrease, $\mathrm{mm} \mathrm{Hg}$, median (IQR) & $-10(-15$ to -7.5$)$ \\
\hline MAP to MAP decrease, mm Hg, median (IQR) & $-5 \quad(-5$ to -5$)$ \\
\hline \multicolumn{2}{|c|}{$\begin{array}{l}\text { Note: } \mathrm{Cl}=\text { confidence interval, } \mathrm{IQR}=\text { interquartile range, } \mathrm{MAP}=\text { mean arterial } \\
\text { pressure, } \mathrm{SAP}=\text { systolic arterial pressure. } \\
{ }^{\circ} \text { Denominator is no. of patients who had new targets of the same blood pressure } \\
\text { variable. }\end{array}$} \\
\hline
\end{tabular}


Table 6: Multivariable logistical model of modifications to blood pressure targets for vasopressor titration during the first 48 hours of intensive care unit stay $(n=277)$

\begin{tabular}{|c|c|c|}
\hline Variable & \multicolumn{2}{|c|}{ OR $(95 \% \mathrm{Cl})$} \\
\hline & \multicolumn{2}{|c|}{$\begin{array}{l}\text { SAP or MAP increased }(n=33) \\
\text { V. no change }(n=197)\end{array}$} \\
\hline Centre 1 v. 3 & 0.79 & (0.30 to 2.04$)$ \\
\hline Centre 2 v. 3 & 0.34 & (0.1 to 1.12$)$ \\
\hline $\begin{array}{l}\text { Acute renal failure v. no acute } \\
\text { renal failure }\end{array}$ & 1.46 & (0.65 to 3.29$)$ \\
\hline $\begin{array}{l}\text { Myocardial infarction v. no } \\
\text { myocardial infarction }\end{array}$ & 1.06 & (0.43 to 2.65$)$ \\
\hline Lactic acid $\geq 4$ v. $<4 \mathrm{mmol} / \mathrm{L}$ & 0.75 & (0.32 to 1.79$)$ \\
\hline \multirow{2}{*}{$\begin{array}{l}\text { Cardiac arrhythmia v. no } \\
\text { arrhythmia }\end{array}$} & 0.96 & (0.39 to 2.38$)$ \\
\hline & \multicolumn{2}{|c|}{$\begin{array}{c}\text { SAP or MAP decreased }(n=47) \\
\text { v. no change }(n=197)\end{array}$} \\
\hline Centre 1 v. 3 & 0.95 & (0.42 to 2.15$)$ \\
\hline Centre 2 v. 3 & 0.55 & (0.20 to 1.51$)$ \\
\hline $\begin{array}{l}\text { Acute renal failure v. no acute } \\
\text { renal failure }\end{array}$ & 1.19 & (0.60 to 2.39$)$ \\
\hline $\begin{array}{l}\text { Myocardial infarction v. no } \\
\text { myocardial infarction }\end{array}$ & 0.68 & $(0.30$ to 1.53$)$ \\
\hline Lactic acid $\geq 4 \mathrm{v} .<4 \mathrm{mmol} / \mathrm{L}$ & 1.44 & (0.72 to 2.89$)$ \\
\hline $\begin{array}{l}\text { Cardiac arrhythmia v. no } \\
\text { arrhythmia }\end{array}$ & 1.15 & $(0.54$ to 2.44$)$ \\
\hline $\begin{array}{l}\text { Note: } \mathrm{Cl}=\text { confidence interval, MAP } \\
\text { SAP = systolic arterial pressure. }\end{array}$ & arterial & $\mathrm{OR}=$ odds ratio, \\
\hline
\end{tabular}

survey, intensivists self-reported adapting blood pressure targets for certain chronic comorbidities and acute concurrent illnesses (e.g., chronic hypertension). ${ }^{12}$ The results of the current observational study describe actual practices and contradict this aspect of the previous survey. Observational data better reflect actual practice than a self-administered survey, and the current results highlight discrepancies between actual practices and physicians' perceptions.

Our data refuted our initial hypothesis that many vasopressor prescriptions would not follow explicit titration orders. These orders consistently involve 1 or a combination of blood pressure targets. The fact that chronic comorbidities, illness severity and individual acute concurrent illnesses were not associated with how physicians prescribed vasopressors in septic shock could mean that, contrary to perceptions and the results of a survey recently published by our group, ${ }^{12}$ these variables are not taken into consideration. Alternatively, these variables may play an important role in the selection of titration targets, but this signal may disappear due to disagreement between physicians in their interpretations. The frequent target modifications we found may underestimate the total number of modifications, because the data collection for this study focused only on the first 48 hours of ICU stay. This suggests that physicians adjust vasopressors based on their perception of the patients' requirements and implies that clinical decisions rely on surrogate end points, although we could not identify them.

\section{Strengths and limitations}

Strengths of our study include a data extraction process that involved rigorous manual review of every included chart as well as detailed instructions and prepiloted electronic data forms with logical checks ensuring data integrity. The multicentre nature of the study improves the generalizability of our results.

Limitations include our reliance on information available in medical records. Chart completeness regarding chronic comorbidities and vasopressor titration targets as well as the intensity of diagnostic workups may have varied across participating centres and between patients. Detailed information about the identity of the individuals (e.g., attending intensivists, fellows, residents, consultants) ordering vasopressors could not be obtained retrospectively. The impact of different individuals on modifications to blood pressure targets could not be taken into account. Although the decision to include or exclude data from a given chart involved a careful manual review of eligibility criteria, different hospitals use different databases and so the screening process may have resulted in different patient populations at the different centres.

\section{Conclusion}

Vasopressors are potent medications with substantial adverse effect profiles and are systematically prescribed to the most vulnerable patients. Thus, identifying a titration strategy that will maximize benefit and minimize harm constitutes a research priority. Future steps should involve the following: developing a better understanding of the rationale underlying vasopressor titration; observing whether actual blood pressure values correspond to set targets; validating that different titration strategies lead to predictable results regarding surrogate end points of organ perfusion and function; and comparing the effects of different titration strategies on clinically important end points in a randomized controlled trial.

\section{References}

1. Angus DC, Linde-Zwirble WT, Lidicker J, et al. Epidemiology of severe sepsis in the United States: analysis of incidence, outcome, and associated costs of care. Crit Care Med 2001;29:1303-10.

2. Kumar G, Kumar N, Taneja A, et al. Nationwide trends of severe sepsis in the 21st century (2000-2007). Chest 2011;140:1223-31.

3. Kirchheim HR, Ehmke H, Hackenthal E, et al. Autoregulation of renal blood flow, glomerular filtration rate and renin release in conscious dogs. Pflugers Archiv 1987;410:441-9.

4. Hollenberg SM. Vasopressor support in septic shock. Chest 2007;132:1678-87.

5. Hollenberg SM. Vasoactive drugs in circulatory shock. Am 7 Respir Crit Care Med 2011;183:847-55.

6. Hollenberg SM, Ahrens TS, Annane D, et al. Practice parameters for hemodynamic support of sepsis in adult patients: 2004 update. Crit Care Med 2004;32: 1928-48.

7. Dellinger, RP, Levy MM, Rhodes A, et al. Surviving Sepsis Campaign: international guidelines for management of severe sepsis and septic shock: 2013. Crit Care Med 2013;41:580-637.

8. Bourgoin A, Leone M, Delmas A, et al. Increasing mean arterial pressure in patients with septic shock: effects on oxygen variables and renal function. Crit Care Med 2005;33:780-6.

9. Dünser MW, Ruokonen E, Pettila V, et al. Association of arterial blood pressure and vasopressor load with septic shock mortality: a post hoc analysis of a multicenter trial. Crit Care 2009;13:R181.

10. LeDoux D, Astiz ME, Carpati CM, et al. Effects of perfusion pressure on tissue perfusion in septic shock. Crit Care Med 2000;28:2729-32.

11. Subramanian S, Yilmaz M, Rehman A, et al. Liberal vs. conservative vasopressor use to maintain mean arterial blood pressure during resuscitation of septic shock: an observational study. Intensive Care Med 2008;34:157-62. 
12. Lamontagne F, Cook DJ, Adhikari NK, et al: Vasopressor administration and sepsis: a survey of Canadian intensivists. 7 Crit Care 2011;26:532.

13. Knaus WA, Draper EA, Wagner DP, et al. APACHE II: a severity of disease classification system. Crit Care Med 1985;13:818-29.

Affiliations: Centre hospitalier universitaire de Sherbrooke (St-Arnaud, Éthier, Lamontagne, Leclair), Sherbrooke, Que.; Centre de recherche Étienne-Le Bel (Éthier, Lamontagne), Université de Sherbrooke, Sherbrooke, Que.; Hamilton Health Sciences (Hamielec), Hamilton, Ont.; Flinders Medical Centre (Bersten, Patel), Adelaide, Australia; Departments of Medicine and Clinical Epidemiology and Biostatistics (Guyatt, Meade, Zhou), McMaster University, Hamilton, Ont.
Contributors: All authors but Andrew Bersten contributed to the conception and design of the study; Charles St-Arnaud, François Lamontagne, Jean-François Ethier and Andrew Bersten contributed to the collection of data; Charles St-Arnaud, François Lamontagne and Qi Zhou contributed to the analysis or interpretation of data. Charles St-Arnaud and François Lamontagne drafted the manuscript, which all of the other authors revised. All authors gave final approval of the version submitted for publication.

Supplemental information: For reviewer comments and the original submission of the manuscript, please see www.cmajopen.ca/content/1/4 /E127/suppl/DC1. 